\section{The Role of Assisted Living Capacity on Nursing Home Financial Performance}

\author{
Justin Lord, MBA, CMA, FHFMA'(D), Ganisher Davlyatov, MPH ${ }^{2}$, \\ Kali S. Thomas, PhD $^{3}$, Kathryn Hyer, PhD, MPP ${ }^{4}$, \\ and Robert Weech-Maldonado, PhD $^{2}$ (iD)
}

INQUIRY: The Journal of Health Care Organization, Provision, and Financing Volume 55: $1-12$

(C) The Author(s) 2018 Article reuse guidelines: sagepub.com/journals-permission DOI: I0.II77/0046958018793285 journals.sagepub.com/home/inq

(SAGE

\begin{abstract}
The rapid growth of the assisted living industry has coincided with decreased levels of nursing home occupancy and financial performance. The purpose of this article is to examine the relationships among assisted living capacity, nursing home occupancy, and nursing home financial performance. In addition, we explore whether the relationship between assisted living capacity and nursing home financial performance is mediated by nursing home occupancy. This research utilized publicly available secondary data, for the state of Florida from 2003 through 20I5. General descriptive statistics were used to assess the relationships among financial performance, assisted living capacity, and occupancy. To explore the relationships among financial performance, assisted living capacity and occupancy, and test potential mediation of occupancy, we followed Baron and Kenny's approach and estimated 3 models examining the relationships between (I) assisted living capacity and nursing home financial performance, (2) assisted living capacity and nursing home occupancy, and (3) nursing home occupancy and financial performance after assisted living capacity is included in the model. We used generalized estimating equations, to adjust for repeated measures and to model the above relationships. Year fixed effects control for time trend. The independent variable, assisted living beds, was lagged for I year to account for the potential influence on financial performance. The final analytic sample consisted of 7688 nursing home-year observations from 657 unique nursing homes. Our findings suggest that assisted living capacity does have a negative impact on nursing homes' financial performance. Even though, assisted living capacity seems not to significantly decrease nursing home occupancy. The relationship between assisted living capacity and financial performance was not mediated through occupancy. These findings suggest that assisted living communities may not be able to significantly reduce nursing home occupancy; however, the presence of assisted living communities may create additional financial/competitive pressures that result in decreased nursing home financial performance.
\end{abstract}

\title{
Keywords
}

assisted living, financial performance, nursing homes, competition

What do we already know about this topic?

The rapid growth of the assisted living industry has coincided with decreased levels of nursing home occupancy and financial performance, yet relatively few studies have examined the impact of assisted living competition on nursing home performance, especially as it relates to occupancy.

How does your research contribute to the field?

This study contributes to the literature by exploring the relationships among assisted living capacity, nursing home occupancy, and nursing home financial performance in the state of Florida from 2003 to 2015.

What are your research's implications toward theory, practice, or policy?

Assisted living communities may not be able to significantly reduce nursing home occupancy; however, the presence of assisted living communities may create additional financial/ competitive pressures that result in decreased nursing home financial performance.

\footnotetext{
'Louisiana State University Shreveport, USA

${ }^{2}$ The University of Alabama at Birmingham, USA

${ }^{3}$ Brown University, Providence, RI, USA

${ }^{4}$ University of South Florida, Tampa, USA
}

Received 3 January 2018; revised July 5 2018; revised manuscript accepted 6 July 2018

\section{Corresponding Author:}

Justin Lord, Doctoral Candidate, James K. Elrod Health Administration Department, Louisiana State University Shreveport, One University Place, Room 30IB, Shreveport, LA 7III5, USA.

Email: Justin.Lord@Isus.edu 


\section{Introduction}

The assisted living/residential care industry has experienced significant growth since its introduction in 1981. ${ }^{1}$ Growth in the assisted living industry has coincided with falling levels of nursing home occupancy. ${ }^{2,3}$ In 1981, nursing home occupancy was around $93 \%$ but has declined to around $82 \%$ in $2014{ }^{4,5}$ During the same period, the number of assisted living/residential care communities grew to around 30200 with an estimated 1 million beds. ${ }^{6}$ The growth of nursing home substitutes, such as assisted living and home- and community-based services (HCBS), has provided more alternatives for individuals seeking long-term care but has also increased the levels of indirect competition within the nursing home industry. The increased levels of competition within the long-term care industry have the potential to impact nursing homes' bottom line. ${ }^{3}$

On average, nursing homes operate on low margins. ${ }^{7}$ Nursing homes must balance the many challenges that can negatively impact their financial position, such as staffing requirements, ${ }^{8}$ falling occupancy rates, ${ }^{9}$ high liability insurance costs, ${ }^{3}$ and state Medicaid reforms. ${ }^{10}$ As such, increased competition from substitute providers may exacerbate a nursing home's weak financial position. The financial performance of a nursing home can have a direct impact on the residents of the nursing home and the community. Nursing homes with poor financial performance have been found to have worse resident quality ${ }^{11,12}$ and be at increased risk of closure and consolidation. ${ }^{3}$

Relatively few studies have examined the impact from assisted living competition on nursing home performance. ${ }^{13}$ These studies have focused on the impact from assisted living competition on nursing home utilization, ${ }^{3}$ nursing home quality ${ }_{1}^{14}$ private-pay prices, ${ }^{13}$ nursing home strategic positioning, ${ }^{15}$ and nursing home case mix. ${ }^{16,3}$ This article contributes to the literature by exploring the relationships among assisted living capacity, nursing home occupancy, and nursing home financial performance in the state of Florida. In addition, we explore whether the relationship between assisted living capacity and nursing home financial performance is mediated by nursing home occupancy. It is important for policy makers and health care leaders to understand the relationship between assisted living supply and nursing homes profitability as this may impact the equitable delivery of long-term care.

The state of Florida was chosen for this study for the following reasons. First, due to its large population of aging individuals. As of 2010, the population estimates of individuals 65 and older in Florida was around $17.3 \%$ as compared with the national average of $13.0 \% .{ }^{17}$ Second, Florida is 1 of 3 states, the others being California and Pennsylvania, that account for $33 \%$ of all assisted living units nationwide. ${ }^{18,19}$ Third, Florida had been very progressive and innovative in funding for longterm care. Florida had introduced its own waiver program, The ALE, that allows low-income individuals to use state Medicaid program dollars to pay for assisted living. ${ }^{20}$ Fourth, there is limited national data on assisted living homes and Florida is one state that actually collects that information.

\section{The Growth of Assisted Living and Nursing Home Care}

Assisted living communities, also called residential care communities, have emerged as a popular housing and longterm care option for older Americans. ${ }^{3,21}$ Although there is no national definition for assisted living communities, they are typically described as organizations that provide 24 hours of supervised care in a residential /homelike setting, yet provide the residents with more independence and autonomy as compared with a nursing home. ${ }^{14}$ Depending on the market and assisted living community, there can be a wide range of diverseness in scope and breadth of services, as well as the populations served by assisted living communities. ${ }^{3,22}$ On average, assisted living communities differentiate themselves from nursing homes by providing care to residents who have a lower level of need as compared with average nursing home residents. ${ }^{14}$ However, over time, some assisted living communities have evolved by providing more intensive care and services for increasingly sick and disabled individuals who have more complex chronic health conditions and less independence. ${ }^{3,23,24}$

Several factors explain the growth in the popularity of assisted living communities. First, there have been increasing federal and state efforts to move individuals from institutional (ie, nursing homes) to noninstitutional or community-based settings. ${ }^{25,26}$ Second, advances in medical technology have altered both demand and need for institutional care. ${ }^{15}$ Third, there has been a consumer preference shift for more independent living. ${ }^{27,28}$ Individuals want to retain their autonomy and independence for as long as possible. The result has been a demand for long-term care services that provide limited assistance for individuals who can no longer live independently but who do not require institutionalized care., ${ }^{2,15}$ Fourth, assisted living communities are generally perceived in a more positive (functional) light relative to nursing homes. A majority of Americans have a negative public perception regarding the quality of care in a nursing home. ${ }^{29}$ Even with increased public reporting of nursing home quality, this has done little to sway consumers. ${ }^{30,31,32}$ Finally, on average, assisted living communities are less costly as compared with nursing homes. ${ }^{33,34}$ According to the Genworth 2010 Cost of Care Survey, the median annual cost of nursing home care in the United States for a semiprivate room in 2010 was $\$ 67525$ but for assisted living care, it was $\$ 38200 .{ }^{34}$ As most assisted living communities are private-pay, consumers who are pricesensitive may choose the option that provides the best value for their dollar. ${ }^{35,3}$

Given the negative public opinion, the high cost,${ }^{34}$ institutional bias, ${ }^{27}$ and cost associated with nursing home care, it is 
little wonder why alternative long-term care providers, such as assisted living communities, have become a popular residential care option for older adults. ${ }^{36,3,15}$

\section{Conceptual Framework}

An organization's ability to accomplish its goals is dependent on the availability of necessary resources. ${ }^{37,38}$ Organizations actively try to obtain critical resources from the environment to ensure continued existence. ${ }^{39}$ Resources that are critical for organizations to function are often scarce and not equally distributed. ${ }^{40}$ The ability to acquire critical resources can be challenging because some critical resources are controlled by other entities/organizations..$^{41,42}$ Resource dependency theory (RDT) states that "the key to organizational survival is the ability to acquire and maintain resources." Uncertainty regarding the availability of resources may explain changes in organizational behavior and performance. ${ }^{42,43}$ Managers must effectively manage their resources and relationships in an ever-changing environment to succeed. ${ }^{44}$ If the environment changes, it is contingent on the organization to stabilize or find new flows of resources. ${ }^{42}$

For many years, nursing homes were the primary source of institutional long-term care; however, over the past several years, there has been increasing levels of direct and indirect competition from within and outside of the nursing home industry. ${ }^{45}$ Assisted living communities and nursing homes both provide long-term care services. In the past, the distinction between nursing home residents and assisted living residents was rather clear-cut. Nursing homes typically had residents with worse acuity and who required more intensive assistance and supervision as compared with assisted living residents. ${ }^{13}$ However, over the past several years, the scope of assisted living care has been expanding. Many assisted living communities are admitting persons with greater levels of physical need and allowing residents to "age in place" longer before discharge to a nursing home. ${ }^{13,24}$ Another big differentiator between assisted living communities and nursing homes has revolved around the payer-mix. Historically, assisted living communities were private-pay, ${ }^{3}$ yet this has started to change with increased funding from Medicaid.

Most states have initiated transfer programs or Medicaid 1915(c) waivers to shift the delivery of long-term care from institutional providers (nursing homes) to residential/community-based long-term care providers. ${ }^{19}$ These programs are responding to the public's consumer desire to receive care in the least restrictive setting possible ${ }^{46}$ and also have been driven by the increasing large percentage that Medicaid long-term spending has on state's budgets. ${ }^{47,19}$ States using the 1915(c) waivers have more flexibility to pay for services traditionally not covered under Medicaid. These waiver programs vary state by state and usually have enrollment caps, waiting lists, or specific state coverages. ${ }^{48}$ Under most 1915 (c) waivers, Medicaid funds cannot be used to pay for basic housing expenses or food in an assisted living community but can be used to reimburse an assisted living community for any service(s) deemed medically necessary. ${ }^{18,19}$ The state of Florida had 2 1915(c) waivers, the assisted living for the elderly (ALE) waiver and the nursing home diversion waiver, that funneled Medicaid dollars to assisted living communities. These waivers were available for assisted living facilities that provided extended congregate care or limited nursing services. ${ }^{49}$ In 2014, Florida discontinued all Medicaid waivers and transformed the program to a Statewide Medicaid Managed Care Long-Term Care (SMMC LTC); however, the assisted living component remained. ${ }^{50}$

\section{Assisted Living as a Potential Substitute of Nursing Home Care}

Competition occurs not only between organizations that offer identical types of products or services but also from organizations that produce similar but different products or services. ${ }^{51,52}$ Dissimilar organizations that are indirect competitors of each other can eventually impact the behavior of each other. ${ }^{13}$ In most cases, assisted living and nursing homes cannot be viewed as pure substitutes for each other, ${ }^{13}$ but, as in the case in Florida, they can provide some overlapping services for individuals seeking long-term care. As assisted living communities increase their breadth and depth of services into long-term care, they can be indirect competitors to nursing homes. Assisted living facilities typically attract healthier, private-pay individuals as compared with nursing homes. ${ }^{3}$ This can implications for nursing homes in regard to "cream skimming." $"$ As assisted living communities attract healthier and private-pay individuals, nursing homes could see a decrease in their private-pay census and a worsening of the average patient acuity. ${ }^{3}$ The loss of private-pay residents and worsening resident acuity could increase costs and reduce the profitability for nursing homes. The threat of increased competition can drive down profitability of an industry. ${ }^{54}$ It is therefore hypothesized that

Hypothesis 1: Increased assisted living capacity will be associated with lower nursing home financial performance.

Assisted living capacity has been found to be negatively associated with nursing home occupancy. ${ }^{3}$ This is due to several factors that were explored earlier in the article, such as increasing federal and state efforts to move individuals from institutional to noninstitutional or community-based settings, ${ }^{25,26}$ shift in consumer preferences for more independent living, ${ }^{27,28}$ perception, ${ }^{29}$ and cost. ${ }^{33,34}$ Previous research has found that increasing assisted living capacity has been associated with declining nursing home occupancy. ${ }^{3}$ The proliferation of long-term care alternatives, such as assisted living providers, can impact the demand for nursing homes, as a market can only support a finite number of organizations. ${ }^{13,55}$ It is therefore hypothesized that 


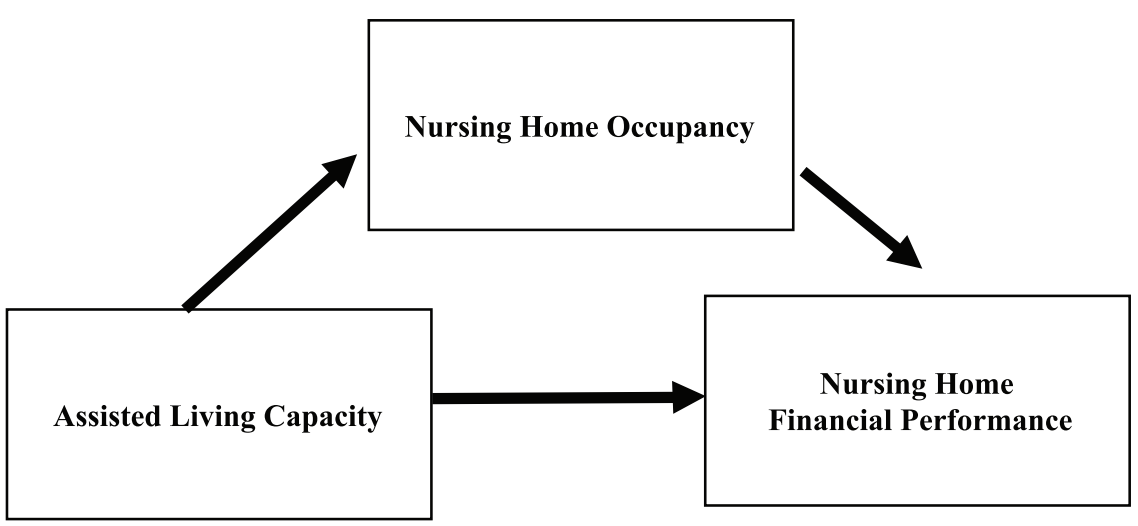

Figure I. Conceptual model.

Hypothesis 2: Increased assisted living capacity will be associated with lower nursing home occupancy rate.

\section{Assisted Living Capacity and Nursing Home Financial Performance: The Mediation Effect of Nursing Home Occupancy}

Prior research has found lower occupancy to be associated with worse nursing home financial performance. ${ }^{9}$ Occupancy is an important metric to examine within nursing homes because of its revenue implications. ${ }^{56}$ Organizations that are producing at their optimal levels, or at full capacity, are better able to cover their fixed costs, which can impact financial performance. Nursing homes with low levels of occupancy will have generated less revenue, which will negatively impact the bottom line. Given the expected relationships between increased assisted living capacity and nursing home occupancy, and the association between occupancy and financial performance, we expect occupancy rate to be a potential mediator between the relationship between assisted living capacity and financial performance. Therefore, we hypothesize that

Hypothesis 3: Increased assisted living capacity will be associated with decreased occupancy rate, and this will in turn result in lower financial performance

These hypothesized relationships are summarized in Figure 1.

\section{Methods}

\section{Data}

This research utilizes data from 4 different sources: Brown University's LTCFocus, Medicare Cost Reports, Area Resource File (ARF), and the State of Florida's list of licensed assisted living communities from 2003-2015.
Brown University's LTCFocus data provide nursing home organizational, demographic, quality, and market information. This dataset is the amalgamation of multiple sources of data, including the Minimum Data Set, CMS's Nursing Home Compare, ARF, Bureau of Labor Statistics, Residential History File, OSCAR/CASPER, and state policy surveys. The Medicare Cost Reports provide financial data for nursing homes that participate in the Medicare program. The ARF dataset contains county-level information on socioeconomic status, population demographics, and environmental characteristics. $^{57}$ The Florida assisted living data are the annual licensed provider lists housed by the Agency for Health Care Administration, ${ }^{58}$ which provided insights into the number and type of assisted living beds operated in the state of Florida for the study period.

\section{Sample}

The sample consisted of all the nursing homes in the state of Florida from 2003 through 2015. There were 8889 nursing home-year observations in Florida from 2003-2015. First, we excluded hospital-based nursing homes observations ( $\mathrm{n}$ $=211$ ). Second, we excluded all nursing homes observations that reported no Medicare payments $(\mathrm{n}=123)$, and other nursing homes observations that had incomplete or skewed financial data $(\mathrm{n}=867)$. Because this study was focused on examining all nursing homes in counties with assisted living capacity, we excluded counties without a licensed assisted living (roughly 7 counties and 76 nursing home observations). This resulted in an analytic sample comprised of 7688 unique nursing home-year observations across the 13 years, with approximately 657 nursing homes in a given year.

\section{Measures}

The dependent variable for hypothesis 1 and 3, financial performance, was operationalized as the operating margin, ${ }^{59,60}$ 
Table I. List of Variables With Datasets.

\begin{tabular}{ll}
\hline Dependent variable & Medicare Cost Reports \\
Nursing home's operating margin & State of Florida \& Area Resource File \\
Independent variables & Brown University's LTCFocus \\
Assisted living beds per 1000 over the age of 65 & \\
Occupancy rate & Brown University's LTCFocus \\
Organizational control variables & Brown University's LTCFocus \\
Chain affiliation (multifacility) & Brown University's LTCFocus \\
Ownership (for-profit) & Brown University's LTCFocus \\
Percent Black & Brown University's LTCFocus \\
Percent Hispanic & Brown University's LTCFocus \\
Percentage of residents covered by health maintenance organization & \\
Acuity index & Brown University's LTCFocus \\
Market control variables & Brown University's LTCFocus \\
Herfindahl index & Brown University's LTCFocus \\
Number of home health agencies per I000 adults & Brown University's LTCFocus \\
Number of short-term hospital beds per I000 adults & Area Resource File \\
\hline $\begin{array}{l}\text { Medicare managed care penetration rate } \\
\text { Educational attainment (less than high-school) }\end{array}$
\end{tabular}

which focuses on core business functions and excludes the influence of nonoperating income like endowments and nonoperating expenses such as interest payments. As such, it measures the percentage profitability as a result of resident revenues and costs. It is calculated as follows:

$$
\text { Operating margin }=\frac{\left(\begin{array}{l}
\text { operating revenue }- \\
\text { operating expenses }
\end{array}\right)}{\text { operating revenue }} .
$$

The dependent variable for hypothesis 2 consists of the occupancy rate, a facility-level variable that represents the number of occupied beds as divided by the total number of beds within a nursing home.

The independent variables included total assisted living beds (hypothesis 1-3) and occupancy rate (mediator in hypothesis 3 ). We specified assisted living beds as the number of beds per 1000 individuals 65 years and older. This variable was lagged for 1 year to account for the potential lagged influence on financial performance. Occupancy rate was calculated as discussed above.

Control variables included organizational and environmental factors that may impact nursing home financial performance. The organizational control variables consisted of chain affiliation, ownership, racial/ethnic resident composition, percentage of residents covered by a Health Maintenance Organization (HMO), and average acuity of residents. Chain affiliation reflects whether the nursing home is part of a chain. Ownership is a dichotomous variable that identifies whether a nursing home is for-profit ( $0=$ not for-profit; $1=$ for-profit). Racelethnicity shows the percentage of nursing home residents who are Black and Hispanic. Percent of residents covered by a HMO identifies the percentage of nursing home residents who are covered by a Medicare HMO in a given year. Acuity index is an average measure of the resident's level of care needed. This measure is based on the number of residents needing various levels of assistance with mobility, activities of daily living (ADL), special treatments, as well as the proportion of residents who are bedfast, exhibit dementia, and who require assistance with ambulation or transfers.

Market control variables included competition, the number of home health agencies, the number of short-term hospital beds, Medicare Advantage penetration rate, and percentage of lower education population at the county level. Competition is measured using the Herfindahl index, which is the squared total number of nursing home beds as divided by the sum of all county beds squared. This is a continuous variable that ranges from 0 to 1 . The closer to 1 , the less competitive the market for nursing homes. The number of home health agencies describes the number of home health agencies in the county for every 1000 persons age 65 or older. Home health care agencies are one mechanism of delivering home and community-based care. Home health care provides less intensive care as compared with nursing homes. The number of short-term hospital beds is the number of short-term general hospital beds in the county for every 1000 persons age 65 or older. Hospitals represent a supplier of residents for nursing homes, particularly for post-acute care. Medicare managed care penetration rate is calculated as the proportion of all Medicare beneficiaries in the county who are enrolled in a Medicare managed care organization (MCO). These organizations attempt to control costs and limit utilization by steering patients to preferred providers. $^{61,62}$ Lower educational attainment is a socioeconomic factor that examines the percentage of the population with less than a high-school education. Table 1 provides a summary of these variables. 
Table 2. Descriptive Statistics for Variables in the Study ( $N=7688$ nursing home-year observations).

\begin{tabular}{ll}
\hline & Mean \\
\hline Dependent variable & \\
Nursing home's operating margin & $11.67 \%$ \\
Independent variables & \\
Assisted living beds per 1000 over the age of 65 & 25.67 \\
Occupancy rate & $88.88 \%$ \\
Organizational control variables & \\
Chain affiliation (multifacility) & $60 \%$ \\
Ownership (for-profit) & $78 \%$ \\
Percent Black & $23.30 \%$ \\
Percent Hispanic & $15.67 \%$ \\
Percentage of residents covered by HMO & $14.66 \%$ \\
Acuity index & 12.14 \\
Market control variables & \\
Herfindahl index & 0.10 \\
Number of home health agencies per I000 adults & 27.91 \\
Number of short-term hospital beds per I000 adults & 18.27 \\
Medicare managed care penetration rate & $28.41 \%$ \\
Educational attainment (less than high-school) & $9.88 \%$ \\
\hline
\end{tabular}

Note. $\mathrm{HMO}=$ health maintenance organization.

\section{Analysis}

Descriptive statistics were examined for all variables included in the analysis. To explore the relationships among financial performance, assisted living capacity and occupancy, and test potential mediation of occupancy, we followed Baron and Kenny's approach and estimated 3 models examining the relationships between (1) assisted living capacity and nursing home financial performance, (2) assisted living capacity and nursing home occupancy, and (3) nursing home occupancy and financial performance after assisted living capacity is included in the model. ${ }^{63}$ We used generalized estimating equations, to adjust for repeated measures at the nursing home facility level and to model the above relationships. Year fixed effects control for time trend. The level of statistical significance was set at $\alpha=0.05$. Stata 13 was used to perform the analysis.

\section{Results}

Table 2 reports the means and standard deviations for all the dependent, independent, and control variables. Nursing homes, in the state of Florida, had a mean operating margin of $11.7 \%$ and an occupancy rate of $88.9 \%$. There was an average of 25.7 assisted living beds per 1000 individuals 65 and older. Sixty percent of the nursing homes were chain affiliated and $78 \%$ of the facilities were classified as for-profit. The percentage of Blacks in a nursing home was around $23.3 \%$, while the percentage of Hispanics was around $15.7 \%$. Around 15\% of all nursing home residents were covered by a Medicare HMO. The average acuity of a nursing home resident was around
12.1. The Herfindahl index, a proxy measure for competition, was around 0.10 , suggesting a highly competitive market. There was an average of 28 home health agencies per 1000 individuals 65 and older and around 18.3 short-term hospital beds for the same population. The Medicare managed care penetration rate was around $28.4 \%$.

\section{Assisted Living Capacity and Nursing Home Financial Performance (model I)}

Table 3 shows the results of the generalized estimating equations for the 3 models. Hypothesis 1 was supported. Assisted living capacity was found to have a statistically significant negative association with nursing homes' financial performance $(P<.05)$ (model 1). For each additional 10 assisted living beds (per 1000 over the age of 65 in the county), nursing homes' operating margin decreased by $1.1 \%$. For-profit $(P<.05)$ and chain affiliated $(P<.01)$ nursing homes were associated with higher financial performance. However, nursing homes with a higher percentage of Black residents $(P<.001)$ had worse financial performance. Nursing homes in less competitive markets $(P<.001)$ exhibited higher financial performance. In markets with a higher percentage of Medicare managed care $(P<.001)$ and a greater number of hospital beds $(P<.001)$, the nursing homes exhibited higher financial performance. The other variables, such as percent Hispanic, percent HMO, resident acuity, number of home health agencies, and lower educational attainment were not significantly associated with nursing home financial performance. 
Table 3. Generalized Estimating Equation Linear Regression: Assisted Living Capacity, Nursing Home Occupancy and Financial Performance.

\begin{tabular}{|c|c|c|c|c|c|c|}
\hline & \multicolumn{2}{|c|}{$\begin{array}{c}\text { Model I: Assisted living (IV) } \\
\text { and financial performance } \\
(\mathrm{DV})^{\mathrm{a}}\end{array}$} & \multicolumn{2}{|c|}{$\begin{array}{l}\text { Model 2: Assisted } \\
\text { living (IV) and occupancy } \\
\text { (DV) }\end{array}$} & \multicolumn{2}{|c|}{$\begin{array}{l}\text { Model 3: Assisted living, } \\
\text { occupancy (DV) and } \\
\text { financial performance (IV) }\end{array}$} \\
\hline & Coefficient (SE) & $P$ values & Coefficient (SE) & $P$ values & Coefficient (SE) & $P$ values \\
\hline $\begin{array}{l}\text { Assisted living capacity } \\
\text { (per } 1000 \text { over the age of } 65 \text { ) }\end{array}$ & $-0.11(0.05)$ & $.018^{*}$ & $-0.02(0.05)$ & .678 & $-0.11(0.05)$ & $.02 *$ \\
\hline \multicolumn{7}{|l|}{ Organizational variables } \\
\hline Chain affiliation (multifacility) & $1.93(0.75)$ & $.010 * *$ & $-0.06(0.79)$ & .936 & $1.94(0.75)$ & $.010 * *$ \\
\hline Ownership (for-profit) & $2.22(0.95)$ & $.019 *$ & $-1.50(0.99)$ & .129 & $2.40(0.94)$ & $.011 *$ \\
\hline Percent Black & $-0.07(0.02)$ & $.001 * * *$ & $-0.05(0.02)$ & $.033^{*}$ & $-0.07(0.02)$ & $.001 * * *$ \\
\hline Percent Hispanic & $-0.02(0.03)$ & 0.443 & $0.11(0.03)$ & $.001 * * *$ & $-0.03(0.02)$ & .197 \\
\hline Percent HMO & $-0.02(0.03)$ & 0.437 & $0.04(0.03)$ & .125 & $-0.03(0.03)$ & .331 \\
\hline Acuity index & $-0.31(0.34)$ & .365 & $-0.99(0.35)$ & $.005 * *$ & $-0.19(0.33)$ & .578 \\
\hline \multicolumn{7}{|l|}{ Market variables } \\
\hline Competition & I 6.52 (4.28) & $.001 * * *$ & $6.59(4.46)$ & .139 & $15.73(4.25)$ & $.001 * * *$ \\
\hline Home health agencies & $2.84(1.52)$ & .063 & $0.33(1.59)$ & .837 & $2.80(1.5 \mathrm{I})$ & .064 \\
\hline Hospital beds & $0.14(0.41)$ & $.001 * * *$ & $0.11(0.04)$ & $.008 * *$ & $0.12(0.04)$ & $.003 * *$ \\
\hline Medicare MCO & $0.14(0.04)$ & $.001 * * *$ & $-0.08(0.04)$ & .074 & $0.14(0.05)$ & $.001 * * *$ \\
\hline Educational attainment & $-0.35(0.20)$ & .075 & $-0.26(0.21)$ & .210 & $-0.32(0.20)$ & .102 \\
\hline Occupancy & & & & & $0.12(0.04)$ & $.001 * * *$ \\
\hline Constant & \multicolumn{2}{|c|}{ II.36 (4.92) } & \multicolumn{2}{|c|}{$103.75(5.13)$} & \multicolumn{2}{|c|}{$-1.02(6.21)$} \\
\hline
\end{tabular}

Note.Year fixed effects control for time trend. IV = independent variable; DV = dependent variable; HMO = health maintenance organization;

$\mathrm{MCO}=$ managed care organization.

a Model I: Operating margin $=\mathrm{f}$ (assisted living capacity, control variables).

'Model 2: Nursing home occupancy $=\mathrm{f}$ (assisted living capacity, control variables).

${ }^{c}$ Model 3: Operating margin $=f$ (assisted living capacity, nursing home occupancy, control variables).

$* P<.05$. $* * P<.01$. $* * * P<.001$.

\section{Assisted Living Capacity and Nursing Home Occupancy (model 2)}

Hypothesis 2 was not supported. Assisted living capacity was not found to have a statistically significant negative association with nursing occupancy (model 2). In this model, it was the racial/ethnicity variables that had a statistically significant impact on occupancy rate. As the percentage of Black nursing home residents $(P<.05)$ increased, this was negatively associated with nursing home occupancy; however, an increase in the percentage of Hispanic nursing home residents was positively associated with nursing home occupancy $(P<.001)$. The increased acuity of the residents was negatively associated with nursing home occupancy $(P<.01)$. The only market-level factors that positively influenced occupancy was the number of hospital beds $(P<.05)$. The other variables, such as chain affiliation, ownership, percent HMO, competition, number of home health agencies, Medicare managed care penetration rate, and lower educational attainment were not significantly associated with nursing home occupancy.

\section{Assisted Living Capacity, Nursing Home Occupancy and Financial Performance (model 3)}

Hypothesis 3 was not supported. After controlling for occupancy, assisted living capacity still exhibited a statistically significant negative relationship with nursing homes financial performance $(\beta=-0.1123, P<.05)$ (model 3$)$. Even though the hypothesized relationship was not mediated by occupancy rate, it was noted that the significance of the relationship between assisted living and nursing home financial performance decreased after controlling for occupancy rate. Occupancy $(P<.001)$ was found to have a positive association with nursing home financial performance. The organizational variables from the first model kept the same directional relationship with chain affiliation $(P<.01)$ and ownership $(P<.05)$ being positively associated with nursing home financial performance. A higher percentage of Black nursing home residents $(P<.001)$ negatively associated with financial performance. Market-level factors like Medicare managed care $(P<.001)$, number of hospital beds $(P<.01)$, and less competition $(P<.001)$ were found to be positively associated with nursing home financial performance. The other variables, such as percent Hispanic, percent HMO, resident acuity, number of home health agencies, and lower educational attainment were not significantly associated with nursing home financial performance.

\section{Discussion}

The goal of this study was to examine the relationships among assisted living capacity, nursing home occupancy, 
and the financial performance of nursing homes in the state of Florida from 2003-2015. We hypothesized that increased levels of assisted living capacity would be associated with both lower nursing home occupancy and worse nursing home financial performance, and that occupancy may be a mediator between assisted living capacity and financial performance. Our findings suggest that assisted living capacity does have a negative impact on nursing homes' financial performance, and that the relationship between assisted living capacity and financial performance was not mediated through occupancy. However, the increased assisted living supply may create additional financial/competitive pressures, such as more acute residents that can result in decreased nursing home financial performance. In addition, the increase of assisted living supply result in higher operating costs as nursing homes potentially have to increase spending on marketing and other amenities to remain competitive in the market. These findings suggest assisted living is not a "true" substitute service for nursing home care, as it does not impact nursing home occupancy. Yet, assisted living communities could be viewed as another indirect competitor in the long-term care industry, thus potentially dampening the profitability of the existing nursing homes.

Assisted living capacity was not found to significantly lower nursing home occupancy. This may have been a result of nursing homes reacting and adjusting to their environment. It is possible that when nursing homes were facing decreasing occupancy, they evolved and focused more of their business to skilled nursing, as to reduce the potential impact of having fewer long-term care residents. According to the National Health Expenditure Survey, the percent nursing homes' total revenue coming from Medicare has almost doubled from $13 \%$ in 2000 to $24 \%$ in $2015 .{ }^{64}$ The potential loss of long-term care residents may have been tempered with an increase in skilled nursing residents.

It is important to note the relationship between the organizational variables in the selected models. In the first (assisted living and financial performance) and the third model (assisted living, occupancy, and financial performance), chain affiliation and for-profit ownership were both positively and statistically associated with financial performance. Chain-affiliated nursing homes may have greater access to resources and thus better financial performance. For-profit organizations have a responsibility to maximize shareholder wealth, so these organizations may focus on decreasing costs and increasing profitability. Neither of these organizational factors had any impact on occupancy, indicating that financial performance may be under management discretion, while occupancy may be driven by market factors, such as more demand for post-acute care services (ie, higher supply of hospital beds).

In this study, nursing homes that had a higher percentage of Black residents had worse financial performance and occupancy. The financial performance finding was concerning but not surprising given the documented racial disparities in long-term care. ${ }^{65}$ Nursing homes located in areas with large minority populations have been found to have worse financial and operational performance. ${ }^{66,67,68,69}$ In addition, nursing homes with a higher percentage of Black residents had lower occupancy rate. This may be a result of socioeconomic and segregation factors. Blacks are more likely to be placed in nursing homes that have greater financial vulnerability, lower levels of staffing and worse quality, as compared with Whites. ${ }^{69}$ Nursing home quality has been shown to vary with socioeconomic ${ }^{70,71}$ and geographic differences. ${ }^{72,73,74}$ Nursing homes that are located in communities with higher rates of poverty and minorities are likely to have worse quality. ${ }^{75}$ Nursing homes that have worse quality could be less attractive to potential residents and thus have the lower occupancy. This has implications for quality in the delivery of long-term care.

On the contrary, occupancy rate was positively associated with a higher percentage of Hispanic residents. This may be attributed to the growth of the Hispanic population in Florida. The Hispanic population in Florida (24.9\%) is much higher relative to the rest of the United States (17.8\%). ${ }^{76}$ In Florida, Hispanics are the largest minority in Florida ${ }^{77}$; they also have tremendous purchasing power and are the fastest growing consumer segment in Florida. With the recent disasters of Hurricane Irma and Maria, it is forecasted that the migration of Puerto Ricans and others moving to Florida permanently will lead to a permanent net increase of over 53134 Hispanics. ${ }^{78}$ This may explain the increase in occupancy and the percentage of Hispanic residents.

Nursing homes with greater resident acuity were associated with lower occupancy rate. This may be symptomatic of a larger national trend of falling nursing home occupancy and worsening resident acuity. ${ }^{79}$ This may also be reflective of the perceived quality of the nursing home. Individuals make subjective assessments about the quality of nursing home care service through various determining factors. ${ }^{80}$ Worsening resident acuity may be interpreted, by potential residents, as an indicator of resident quality. Individuals may choose to avoid nursing homes that they perceive as having worse care.

The market-level variable, Medicare managed care was positively associated with nursing home financial performance. Although this may seem counterintuitive, it is important to recognize that Medicare post-acute spending has doubled from 2001 to 2013 and now accounts for $10 \%$ of all long-term care spending. ${ }^{81,82,83}$ In 2015, Medicare reimbursements for skilled nursing, post-acute care, on average, accounted for $24 \%$ of a nursing homes revenue. ${ }^{64}$ These dollars represent an increasingly crucial revenue stream for most nursing homes. ${ }^{84}$ As of 2016 , over $30 \%$ of Medicare beneficiaries had their coverage administered through a Medicare MCO ${ }^{85}$ Although Medicare MCOs may attempt to control costs and limit utilization ${ }^{62}$ by restricting provider networks and adjusting post-acute cost-sharing arrangements, ${ }^{85,82}$ their ability to steer Medicare skilled nursing patients may still be financially beneficial for the nursing home. This may help 
explain why their presence has had a positive association with nursing home financial performance.

The Herfindahl index, a proxy for competition was positively associated with financial performance. As the market became more monopolistic, the higher the financial performance of the nursing home. These findings suggest that nursing homes in these markets faced less competition relative to other markets and thus have higher levels of profitability.

An increase in hospital beds was associated with higher financial performance and occupancy within a nursing home. This finding is understandable, given the supply and demand relationship that has developed between freestanding nursing homes and hospitals. Thinking of the supply-demand relationship, nursing homes in markets with a higher number of hospital beds should expect to see more patients who need skilled nursing care after discharge. The influx of patients into nursing homes can have a positive impact on nursing homes occupancy and ultimately financial performance. Nursing homes with a higher Medicare resident census typically have better financial and operating performance. ${ }^{56}$ Nursing homes, that provide skilled nursing care, will want to have favorable relationships with hospitals as to maximize the number of Medicare referrals. Nursing homes will prosper and or suffer based on their ability to gain those resources.

There are several limitations of this study. The observed relationship between assisted living capacity and financial performance may be endogenous. Assisted living communities are located in markets with disproportionally higher educational attainment, income, and wealth. ${ }^{14,86}$ Other factors of competition, supply, demand, or other unobservable variables may be linked to both higher occupancy and better financial performance. Second, our study was limited to respondents in the state of Florida. This state is unique as it relates to the high proportion of aging individuals and the large presence of assisted living communities. ${ }^{18,19}$ Also Florida is unique in that it has recently moved away from the waiver programs and has deployed a SMMC LTC. ${ }^{48}$ These unique factors dealing with the state of Florida may limit the generalizability of these findings. Third, this study did not capture any data on the impact of HCBS, which is an important supplier of long-term care services. Future studies should examine the relationship between assisted living capacity and financial performance among more markets and states. Despite the limitations of this research, this study makes an important contribution to the literature on the examination of the competition through assisted living capacity, nursing home occupancy, and financial performance. Future research needs to examine the future effects of assisted living capacity and of quality care in the nursing home industry. ${ }^{14}$

\section{Conclusion}

Nursing homes often provide long-term care services to some of the nation's sickest, frailest, financially and socially vulnerable individuals in long-term care. ${ }^{87}$ For nursing homes to remain operational, they must remain profitable and financially solvent. In 2012, the average total facility margin was only $2.1 \%$, and with profit margins that low, there is not a lot of room for error. ${ }^{16}$ As this research found, assisted living capacity has the potential to further depress nursing home financial performance.

Nursing home administrators must make decisions to protect the financial viability of nursing homes, while finding ways to deliver high quality care. This is done through a combination of increasing revenue and decreasing costs. Increasing the occupancy rate has been one way to improve a nursing homes financial performance. ${ }^{88}$ However, occupancy rates can be impacted by market factors, such as increased competition. Policy makers need to recognize the potential negative effects that indirect competitors can have on nursing homes. If nursing homes are not able to maintain adequate profit margins, they may ultimately close, which can have future access implications. Additional research is needed to examine the other impacts that increased competition from assisted living can have on nursing home quality, staffing, performance, and survival.

\section{Declaration of Conflicting Interests}

The author(s) declared no potential conflicts of interest with respect to the research, authorship, and/or publication of this article.

\section{Funding}

The author(s) received no financial support for the research, authorship, and/or publication of this article.

\section{ORCID iD}

Justin Lord (iD https://orcid.org/0000-0002-4557-955X

Robert Weech-Maldonado (iD https://orcid.org/0000-0002-5005-0909

\section{References}

1. Kane RA. Long-term care and a good quality of life: bringing them closer together. Gerontologist. 2001;41(3):293-304.

2. Bishop CE. Where are the missing elders? the decline in nursing home use, 1985 and 1995. Health Aff. 1999;18(4):146-155.

3. Grabowski DC, Stevenson DG, Cornell PY. Assisted living expansion and the market for nursing home care. Health Serv Res. 2012;47(6):2296-2315.

4. Harrington C, Swan JH, Grant LA. Nursing home bed capacity in the states, 1978-86. Health Care Financ Rev. 1988;9(4):81-97.

5. Centers for Medicare \& Medicaid Services. National health expenditure data. Published 2015. https://www.cms.gov/ResearchStatistics-Data-and-Systems/Statistics-Trends-and-Reports/ NationalHealthExpendData/NationalHealthAccountsHistorical. html. Accessed August 25, 2018.

6. Harris-Kojetin L, Sengupta M, Park-Lee E, et al. Long-term care providers and services users in the United States: data from the national study of long-term care providers, 20132014. Send to Vital Health Stat 3. 2016;38:x-xii;1-105.

7. Pradhan R, Weech-Maldonado R, Harman JS, Laberge A, Hyer K. Private equity ownership and nursing home financial performance. Health Care Manage Rev. 2013;38(3):224-233. 
8. Bowblis JR. The cost of regulation: more stringent staff regulations and nursing home financial performance. J Regul Econ. 2015;47(3):325-338.

9. Weech-Maldonado R, Laberge A, Pradhan R, Johnson CE, Hyer K. Nursing home financial performance: the role of ownership and chain affiliation. Paper presented at Academy of Management Proceedings; August, 2010.

10. Sparer MS. States in a reformed health system: lessons from nursing home policy. Health Aff. 1993;12(1):7-20.

11. Harrington C, Olney B, Carrillo H, Kang T. Nurse staffing and deficiencies in the largest for-profit nursing home chains and chains owned by private equity companies. Health Serv Res. 2012;47(1, pt 1):106-128.

12. Government Accountability Office. Nursing Home Quality: CMS Should Continue to Improve Data and Oversight. GAO16-33. Washington, DC: Government Accountability Office; 2015 .

13. Bowblis JR. Nursing home prices and market structure: the effect of assisted living industry expansion. Health Econ Policy Law. 2014;9(1):95-112.

14. Bowblis JR. Market structure, competition from assisted living facilities, and quality in the nursing home industry. Appl Econ Perspect Policy. 2012;34(2):238-257.

15. Gruneir A, Lapane KL, Miller SC, Mor V. Long-term care market competition and nursing home dementia special care units. Med Care. 2007;45(8):739-745

16. Clement J. Value and nursing home profitability. Health Serv Manage Res. 2016;29(3):62-69.

17. US Census Bureau. QuickFacts. 2018. https://www.census. gov/quickfacts/fact/table/FL/AGE765210\#viewtop. Accessed August 25, 2018.

18. Mollica RL, Johnson-Lamarche H, O'Keeffe J. State Residential Care and Assisted Living Policy: 2004. US Government Printing Office; 2005.

19. Street D, Burge S, Quadagno J. The effect of licensure type on the policies, practices, and resident composition of Florida assisted living facilities. Gerontologist. 2009;49(2):211-223.

20. Florida Department of State. Rule \#65A-2.023: Application and Determination of Eligibility. Florida Administrative Code \& Florida Administrative Register; 2017.

21. Hawes C, Rose M, Phillips CD. A National Study of Assisted Living for the Frail Elderly: Results of a National Survey of Facilities. Washington, DC: US Department of Health and Human Services; 1999.

22. Hawes C, Phillips CD, Rose M, Holan S, Sherman M. A national survey of assisted living facilities. Gerontologist. 2003;43(6):875-882

23. Zimmerman S, Sloane PD, Eckert JK. Assisted Living: Needs, Practices, and Policies in Residential Care for the Elderly. JHU Press; 2001.

24. Spillman B, Liu K, McGilliard C. Trends in residential longterm care: use of nursing homes and assisted living and characteristics of facilities and residents. 2002.

25. Meng H, Dobbs D, Wang S, Hyer K. Hospice use and public expenditures at the end of life in assisted living residents in a Florida Medicaid waiver program. J Am Geriatr Soc. 2013;61(10):1777-1781

26. Reinhard SC. Diversion, transition programs target nursing homes' status quo. Health Aff. 2010;29(1):44-48.
27. Mollica RL, Houser AN, Ujvari K. Assisted living and residential care in the states in 2010. 2012.

28. Munn JC, Dobbs D, Meier A, Williams CS, Biola H, Zimmerman S. The end-of-life experience in long-term care: five themes identified from focus groups with residents, family members, and staff. Gerontologist. 2008;48(4):485-494.

29. Foundation TKF. Views About the Quality of Long-term Care Services in the United States. Menlo Park, CA: The Henry J. Kaiser Family Foundation; 2007.

30. Grabowski DC, Town RJ. Does information matter? competition, quality, and the impact of nursing home report cards. Health Serv Res. 2011;46(6, pt 1):1698-1719.

31. Schapira MM, Shea JA, Duey KA, Kleiman C, Werner RM. The nursing home compare report card: perceptions of residents and caregivers regarding quality ratings and nursing home choice. Health Serv Res. 2016;51(suppl 2):1212-1228.

32. Werner RM, Norton EC, Konetzka RT, Polsky D. Do consumers respond to publicly reported quality information? evidence from nursing homes. J Health Econ. 2012;31(1):50-61.

33. Brodie M, Blendon R. National Survey on Nursing Homes. Menlo Park, CA: Kaiser Family Foundation/NewsHour with Jim Lehrer; 2001

34. Financial G. Genworth 2010 cost of care survey. Richmond, VA: Genworth Financial; 2010.

35. Doty P. The evolving balance of formal and informal, institutional and non-institutional long-term care for older Americans: a thirty-year perspective. Public Policy and Aging Report. 2010;20(1):3-9.

36. Meyer H. The bottom line on assisted living. Hosp Health Network. 1998;72(14):22-26.

37. Arbab Kash B, Spaulding AD, Gamm LD, Johnson C. Healthcare strategic management and the resource based view. Journal of Strategy and Management. 2014;7(3):251-264.

38. Rangan VK. Lofty missions, down-to-earth plans. Harvard Bus Rev. 2004;82(3):112-119.

39. Kotter JP. Managing external dependence. Acad Manage Rev. 1979;4(1):87-92.

40. Pennings JM. The relevance of the structural-contingency model for organizational effectiveness. Admin Sci Quart. $1975 ; 20: 393-410$

41. Jacobs D. Dependency and vulnerability: an exchange approach to the control of organizations. Admin Sci Quart. 1974;19:4559.

42. Pfeffer J, Salancik GR. The External Control of Organizations: A Resource Dependence Approach. New York, NY: Harper \& Row; 1978.

43. Ulrich D, Barney JB. Perspectives in organizations: resource dependence, efficiency, and population. Acad Manage Rev. 1984;9(3):471-481

44. Scott WR, Davis GF. Organizations and Organizing: Rational, Natural and Open Systems Perspectives. Routledge; 2015.

45. Clement JP, Khushalani J. Does assisted living capacity influence case mix at nursing homes? Gerontol Geriatr Med. 2015; 1-8. doi:10.1177/2333721415587449.

46. Kane RL, Kane RA. What older people want from long-term care, and how they can get it. Health Aff. 2001;20(6):114-127.

47. Smith V, Ramesh R, Gifford K, Ellis E, Rudowitz R, O’Malley M. The Continuing Medicaid Budget Challenge: State Medicaid Spending Growth and Cost Containment in Fiscal Years 2004 
and 2005. Menlo Park, CA: Kaiser Commission on Medicaid and the Uninsured; 2004.

48. Paying for Senior Care. Medicaid's assisted living benefits: availability and eligibility. In: Paying for Senior Care, ed. Published April 2018. https://www.payingforseniorcare.com/ medicaid-waivers/assisted-living.html. Accessed April 5, 2018.

49. Mollica RL, Simms-Kastelein K, Kassner E. State-Funded Home and Community-Based Services Programs for Older Adults. Washington, DC: American Association of Retired Persons (AARP) Public Policy Institute; 2009.

50. Department of Elder Affairs State of Florida. Medicaid longterm care services. Published 2018. http://elderaffairs.state. fl.us/doea/medicaid waiver.php. Accessed July 25, 2018.

51. Nyman JA. The effects of market concentration and excess demand on the price of nursing home care. J Ind Econ. 1994;42:193-204.

52. Abraham J, Gaynor M, Vogt WB. Entry and competition in local hospital markets. $J$ Ind Econ. 2007;55(2):265-288.

53. Berta P, Callea G, Martini G, Vittadini G. The effects of upcoding, cream skimming and readmissions on the Italian hospitals efficiency: a population-based investigation. Econ Model. 2010;27(4):812-821.

54. Porter ME. The five competitive forces that shape strategy. Harvard Bus Rev. 2008;86(1):25-40.

55. Gabszewicz JJ, Thisse J-F. Entry (and exit) in a differentiated industry. J Econ Theory. 1980;22(2):327-338.

56. Zinn JS, Mor V, Feng Z, Intrator O. Doing better to do good: the impact of strategic adaptation on nursing home performance. Health Serv Res. 2007;42(3, p 1):1200-1218.

57. Health Resources \& Services Administration (HRSA). Area health resources files. Washington, DC: US Department of Health and Human Services; 2017.

58. FloridaHealthFinder.gov. Facility/provider locator. Published 2018. http://www.floridahealthfinder.gov/facilitylocator/Facility Search.aspx. Accessed July 25, 2018.

59. Pink GH, Holmes GM, D’Alpe C, Strunk LA, McGee P, Slifkin RT. Financial indicators for critical access hospitals. $J$ Rural Health. 2006;22(3):229-236.

60. Weech-Maldonado R, Neff G, Mor V. The relationship between quality of care and financial performance in nursing homes. J Health Care Finance. 2003;29(3):48-60.

61. Reaves EL, Musumeci M. Medicaid and Long-term Services and Supports: A Primer. Washington, DC: The Kaiser Family Foundation; May 2015:8.

62. Zinn JS, Mor V, Castle N, Intrator O, Brannon D. Organizational and environmental factors associated with nursing home participation in managed care. Health Serv Res. 1999;33(6):1753-1767.

63. Baron RM, Kenny DA. The moderator-mediator variable distinction in social psychological research: conceptual, strategic, and statistical considerations. J Pers Soc Psychol. 1986;51(6):1173-1182.

64. Centers for Medicare \& Medicaid Services. CMS expenditure data. Published 2017. https://www.cms.gov/ResearchStatistics-Data-and-Systems/Statistics-Trends-and-Reports/ NationalHealthExpendData/index.html. Accessed July 25, 2018.

65. Chisholm L, Weech-Maldonado R, Laberge A, Lin FC, Hyer $\mathrm{K}$. Nursing home quality and financial performance: does the racial composition of residents matter? Health Serv Res. 2013;48(6, pt 1):2060-2080.
66. Angelelli J, Grabowski DC, Mor V. Effect of educational level and minority status on nursing home choice after hospital discharge. Am J Public Health. 2006;96(7):1249-1253.

67. Grabowski DC. A longitudinal study of Medicaid payment, private-pay price and nursing home quality. Int $J$ Health Care Finance Econ. 2004;4(1):5-26.

68. Tamara Konetzka R, Grabowski DC, Perraillon MC, Werner RM. Nursing home 5-star rating system exacerbates disparities in quality, by payer source. Health Aff. 2015;34(5):819827.

69. Smith DB, Feng Z, Fennell ML, Zinn JS, Mor V. Separate and unequal: racial segregation and disparities in quality across US nursing homes. Health Aff. 2007;26(5):1448-1458.

70. Firebaugh G, Acciai F. For blacks in America, the gap in neighborhood poverty has declined faster than segregation. Proc Natl Acad Sci U S A. 2016;113:13372-13377.

71. Rahman M, Foster AD. Racial segregation and quality of care disparity in US nursing homes. J Health Econ. 2015;39:1-16.

72. Welch WP, Miller ME, Welch HG, Fisher ES, Wennberg JE. Geographic variation in expenditures for physicians' services in the United States. New Engl J Med. 1993;328(9): 621-627.

73. Baicker K, Chandra A, Skinner JS, Wennberg JE. Who you are and where you live: how race and geography affect the treatment of Medicare beneficiaries. Health Aff. 2004: Web Exclusive: VAR33-VAR44.

74. Rahman M, Grabowski DC, Gozalo PL, Thomas KS, Mor V. Are dual eligibles admitted to poorer quality skilled nursing facilities? Health Serv Res. 2014;49(3):798-817.

75. Feng Z, Lepore M, Clark MA, et al. Geographic concentration and correlates of nursing home closures: 1999-2008. Arch Intern Med. 2011;171(9):806-813.

76. US Census Bureau. QuickFacts. The United States Census Bureau. Published 2017. https://www.census.gov/quickfacts/ fact/table/US/PST045216. Accessed July 25, 2018.

77. Vogel M. Florida's Hispanic population. Florida Trend. April 30, 2013. http://www.floridatrend.com/article/15528/floridashispanic-population?page=1. Accessed July 25, 2018.

78. Summary E. Demographic Estimating Conference: Florida Demographic Forecast. Office of Economic and Demographic Research; Tallahassee, FL: 2017.

79. Feng Z, Grabowski DC, Intrator O, Mor V. The effect of state Medicaid case-mix payment on nursing home resident acuity. Health Serv Res. 2006;41(4, p 1):1317-1336.

80. Steffen TM, Nystrom PC. Organizational determinants of service quality in nursing homes. $J$ Healthc Manag. 1997;42(2):179-191.

81. Eiken S, Sredl K, Burwell B, Saucier P. Medicaid expenditures for long-term services and supports (LTSS) in FY 2013: home and community-based services were a majority of LTSS spending. Cambridge, MA: Truven Health Analytics. 2015;79.

82. Keohane LM, Grebla RC, Rahman M, et al. First-dollar costsharing for skilled nursing facility care in Medicare advantage plans. BMC Health Serv Res. 2017;17(1):Article 611.

83. Commission MPA. Section 8: post acute care, a data book: health care spending and the Medicare program. Published 2017. http://www.medpac.gov/docs/default-source/data-book/ jun17_databooksec8_sec.pdf. Accessed August 24, 2017. 
84. Qaseem A, Weech-Maldonado R, Mkanta W. The Balanced Budget Act (1997) and the supply of nursing home subacute care. J Health Care Finance. 2007;34(2):38-47.

85. Jacobson G, Damico A, Neuman T, Gold M. Medicare Advantage 2015 Spotlight: Enrollment Market Update. Menlo Park, CA: The Henry J. Kaiser Foundation; 2015. https://www. kff.org/medicare/issue-brief/medicare-advantage-2015-spotlight-enrollment-market-update/ Accessed December 18, 2015.
86. Stevenson DG, Grabowski DC. Sizing up the market for assisted living. Health Aff. 2010;29(1):35-43.

87. Castle NG. Nursing home closures, changes in ownership, and competition. Inquiry. 2005;42(3):281-292.

88. Harrington C, Hauser C, Olney B, Rosenau PV. Ownership, financing, and management strategies of the ten largest forprofit nursing home chains in the United States. Int J Health Serv. 2011;41(4):725-746. 